\title{
ECOSYSTEM SERVICES AND PAYMENTS FOR ENVIRONMENTAL SERVICES: TWO SIDES OF THE SAME COIN?
}

\section{Denis Pesche, Marie Hrabanski, Philippe Méral \& Marie Bonnin}

The topic of ecosystem services, ecological services, environmental services (ES) and payments for environmental services (PES) has recently become the main reference for international environmental policies (broadly including forest policy, agro-environmental measures, conservation policies etc.).

Brought to media attention by the Millennium Ecosystem Assessment (MA) in 2005, these notions have spread rapidly in both political and scientific arenas. But there has been very little analysis retracing the social construction and political scope of these concepts in the scientific and policy fields. It is as if thinking in terms of ecosystem services and promoting payments for environmental services were taking for granted. This paper seeks to fill this gap, offering a historical and institutional analysis that explores the relationship between the ES and PES concepts.

We put forward the hypothesis that two relatively independent processes led to the emergence of the ES concept on one hand and the PES concept on the other. Whereas the concept of ES is closely linked to a desire to attract official attention to the threats to ecosystems posed by human pressure, the concept of PES seems rather to have stemmed from a concern to ensure funding for conservation in tropical countries over the long term. In the past few years the two concepts have gradually converged, apparently due to a shared desire to translate them into operational form through public policy instruments.

Taking a multidisciplinary approach combining political science, sociology, economics and law, we aim to substantiate this hypothesis using the notion of an epistemic configuration, derived from that of an epistemic community (Haas, 1992), to highlight the composite nature of the networks involved in the emergence and promotion of PES schemes.

In the first section below, we study the genesis of the concepts of ES and PES, showing how the two terms are connected with different epistemic configurations. In the second section, we show how the two concepts have converged at the international level, during the MA process but mainly afterwards. In the third section, we try to identify new trends and ongoing processes concerning ES and PES. 